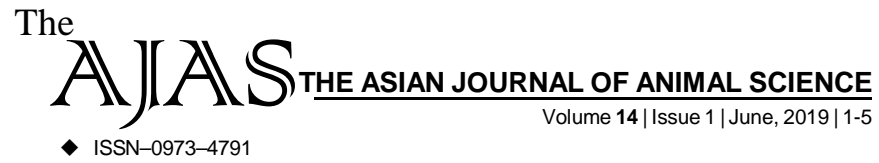

DOI : 10.15740/HAS/TAJAS/14.1/1-5 Visit us | www.researchjournal.co.in

RESEARCH ARTICLE.

\title{
Effect of mineral mixture feeding on the productive and reproductive performance and feed economics of rathi cow under field conditions in Bikaner district of Rajasthan
}

Upendra Kumar and Vishal Kumar Jain

Author for Corresponding -

\section{Upendra Kumar}

Krishi Vigyan Kendra (SKRAU),

Bikaner (Rajasthan) India

Email: ukmeel@gmail.com

\begin{abstract}
A field study was conducted to identify effect of mineral mixture feeding on the production and reproductive performance of rathi cow. 50 animals were selected and divided in to two groups of 25 animals each. First group (T) was fed with $50 \mathrm{~g}$ mineral mixture daily till 90 days of lactation. Other group (C) was kept devoid from additional mineral mixture feeding which is farmer practice in that particular area. Average milk yield recorded during the study was period $4.42 \pm 0.43$ and $5.57 \pm 0.39$ lit per day in $C$ and $T$ groups, respectively. The results indicated that the rathi cow supplemented with mineral mixture and common salt produced 26.02 per cent more milk as compared to control without any adverse affect on the body weight and health of the animals. The increase in milk yield was significantly higher $(\mathrm{P}<0.05)$ in the animals of supplemented group as compared to control. Milk production and reproductive parameters like days of first postpartum estrus, service period, service per conception, conception rate were compared between treatment and control groups. Mineral mixture fed group had edge on control group in respect to reproductive efficiency. In which days of first post-partum estrus and conception rate were found significantly $(\mathrm{P} \leq 0.05)$ shorter and higher, respectively in treatment group compared to control group. Finding of this experiment suggest that continuous feeding of mineral mixture bettered performance of dairy rathi cow in respect of their production and reproductive performance.
\end{abstract}

KEY WORDS...... Mineral mixture feeding, Productive, Reproductive performance, Rathi cow, Feed economics

HOW TO CITE THIS ARTICLE - Kumar, Upendra and Jain, Vishal Kumar (2019). Effect of mineral mixture feeding on the productive and reproductive performance and feed economics of rathi cow under field conditions in Bikaner district of Rajasthan. Asian J. Animal Sci., 14(1): 1-5. DOI : 10.15740/HAS/ TAJAS/14.1/1-5. Copyright@ 2019: HindAgri-Horticultural Society.

ARTICLE CHRONICLE - Received : 09.04.2019; Revised : 01.05.2019; Accepted : 14.05.2019 